\title{
USENET Discussion Groups in Political Science Courses
}

\author{
Martha Bailey, Southern Illinois University-Edwardsville
}

Network news-or "netnews"-is divided into hundreds of newsgroups on a variety of topics, some more technical than others. Most useful to political science students, however, are the groups on politics and on culture. Users can post messages to USENET groups which are then transmitted to all machines in the world which carry each particular group. A user with a question or an opinion could start a discussion that could eventually be read by hundreds or thousands of people throughout the world (Tanenbaum 1989).

In my Introduction to American Politics class, students have e-mail accounts and also access USENET newsgroups that discuss American politics. The wide variety of discussion groups that are suitable include the "talk.politics" hierarchy, featuring talk.politics.misc., talk. politics.theory, talk.politics.abortion, and talk.politics.mideast, to name a few. Newsgroups are categorized by their area of concentration. (For a more complete discussion, see Kehoe's Zen \& the Art of the Internet, available electronically from ftp.eff.org in the directory /pub/Publications/Net guidebooks/Zen_and_Internet.)

Here are the "Big Seven" - the major categories:

1. comp-topics of interest to computer professionals and hobbyists

2. sci-topics of interest to scientific professionals; noncomputer technical topics

3. news-policy and "housekeeping" matters with regard to network news, such as proposals for new groups, maintenance, and usage statistics

4. rec-groups oriented toward recreation and hobbies

5. misc-miscellaneous, including job listings

6. soc-groups concerned with social issues and culture, worldwide

7. talk-groups concerned with debate (on political topics, among others)

The two categories, "soc" and "talk," are probably the most useful for incorporating into political science courses. The categories "alt" and "bit" (not discussed here) may also be relevant.

\section{USENET in Introduction to American Politics}

In my Introduction to American Politics course at Old Dominion University in fall 1993, all students were issued mainframe computer accounts. One full session in our teaching computer laboratory served as an introduction for logging on the computer, accessing USENET newsgroups, and learning which groups were most relevant to discussing topics dealing with American politics. Since the class was too large for everyone to be at a computer at once, I cycled the class through in two equally sized groups. My preparation for this session consisted of about two hours of work in accessing the system and identifying relevant groups. I also conducted a practice session in the lab in which I would be instructing students.

Some students experience anxiety learning to use the computer. The best way to assuage apprehension is to be comfortable yourself with the commands and software and to proceed slowly. By the midpoint of the semester, just about every student was comfortable with the basics of logging on and accessing news groups. Outside of classroom time, I provided a small amount of personal tutoring during regular office hours. Those with teaching assistants could no doubt delegate this duty to others. The newsgroups available on my system that I believed to be the most useful for my course were talk.politics. misc, talk.politics.theory, soc.culture.usa, and soc.women.
Students get hooked when they find something of special interest or with which they identify-a discussion of current films, tour dates for the Grateful Dead, or the Mexican discussion group, for instance. I do not discourage them from prowling the net for recreational groups or information, so long as they are completing their assignments in my course on schedule.

The first assignment involved writing a policy paper on a current issue. The second assignment was an analysis using presidential press releases. For the policy paper, students were required to follow a "thread" (discussion topic) in one of the newsgroups and to discuss and respond to the arguments featured. For example, during one class, a heated discussion on talk. politics.misc dealt with drug legalization. The points of view expressed in such a "thread" could be included in a policy paper on the topic.

Students should be aware that comments on USENET are likely not representative of the general population, and that for research purposes USENET should be supplemented with other materials, such as public opinion polls with randomized samples, national newspapers, and academic journals. As with any source, material from USENET discussions must be properly acknowledged. This gets a bit tricky, however, as there is no authoritative source on proper citation from USENET. I generally require the citation of the poster's name (where possible), "Subject:" line, news group, date. For example, Helen Pauley, "Clinton's Foreign Policy," USENET news group talk.politics.misc, 8/19/94. Each message has a unique identification number that could also be included. It is likely that citation guidelines for Internet sources will eventually be included in style manuals.

With regard to USENET, be forewarned that some discussion 
consists of heated debate with little resolution and many "flames" (attacks). Posts may be more emotional than factual, and personality conflicts and ad hominem attacks are common. I encourage students to participate in the newsgroup should they be so moved, though I recommend that students "lurk" (read without posting messages) on a newsgroup for a time before participating in the discussion. This allows students to get a sense of what the newsgroup is like before jumping into the debate. Most of my students don't post to groups early in the course since I discourage it. Later in the semester a few brave souls chose to post.

Another good idea is to obtain the group's "FAQ" (Frequently Asked Questions), if it has one. FAQs are occasionally posted in relevant newsgroups and in news. answers; many are available through FTP (File Transfer Protocol) from $\mathrm{rtfm}$.mit.edu in the directory /pub/usenet.

Presidential news releases can be obtained through electronic-mail subscription, but in my course we read them on talk.politics.misc, among other groups. The opportunity to view the same releases available to the Washington press corps is exciting to students. I taught my students to access the releases, read them on USENET, and save and print the files at the computer center on campus. For one assignment, students compared a press release (on an attentiongetting topic) with the way the news was reported in the national press.

In comparing a news release with stories in the New York Times, the Washington Post, and stories from the AP wire, students were often surprised to see how much material was taken directly from the press release. Some students noted the sheer amount of material released (announcement of new political appointees, etc.) and how many of the releases concerned stories of regional interest (for example, the president's address to a community group in a distant state).

Instructors of comparative politics or international relations courses might want to employ other groups, such as talk.politics. mideast, or soc.rights.human, along with any of the relevant soc.culture groups. Some of the newsgroups focus on more controversial topics, such as talk.politics.animals or talk.abortion. Depending on how much conflict you can tolerate (or how courageous you're feeling), these groups offer lively debate, to say the least.

\section{Conclusion}

Incorporating USENET into political science courses has many advantages, and I believe that experiencing the world of USENET can be life changing. Much of the time, the discussion on talk.politics newsgroups (for example) is unlikely to win a debate tournament on either technical or substantive merit. Nonetheless, discussion can be extremely engaging, topical, and comprehensive, and students certainly get the impression that current issues provoke debate. Some USENET discussion threads support the claim that communities may form in "cyberspace," though the members might be widely dispersed in "real-world" space. (Rheingold 1994)

Reference works on the Internet and USENET that instructors may wish to consult include Gaffin (1994), Kehoe (1992), Krol (1994), and Manrique (1993). New books appear frequently, but some amount to no more than listings of newsgroups-you might do better to prowl through the net yourself in the relevant hierarchies discussed earlier.

Network news can enhance traditional course materials. The new technological form captivates students' attention, and the content of discussions is both timely and topical. At the end of the semester, most of the students asked that their computer mainframe accounts be extended so that they could continue participating in USENET newsgroups. This, I believe, is a final testament to the exciting world of the net.

\section{References}

Gaffin, Adam. 1994. EFF's Guide to the Internet, Washington, DC: Electronic Frontier Foundation.

Kehoe, Brendon. 1992. Zen and the Art of the Internet: A Beginner's Guide to the Internet, lst ed.

Krol, Ed. 1994. The Whole Internet: User's Guide and Catalog, 2nd ed., Sebastopol, CA: O'Reilly \& Associates, Inc.

Manrique, Cecilia G. 1993. "Using Internetworking Resources in the Political Science Classroom," paper presented at the 1993 Annual Meeting of the American Political Science Association, Washington, DC, September 2-5.

Rheingold, Howard. 1994. Virtual Community: Homesteading on the Electronic Frontier, New York: Harper-Collins.

Tanenbaum, Andrew S. 1989. Computer Networks, 2nd ed, Englewood Cliffs, NJ: Prentice Hall.

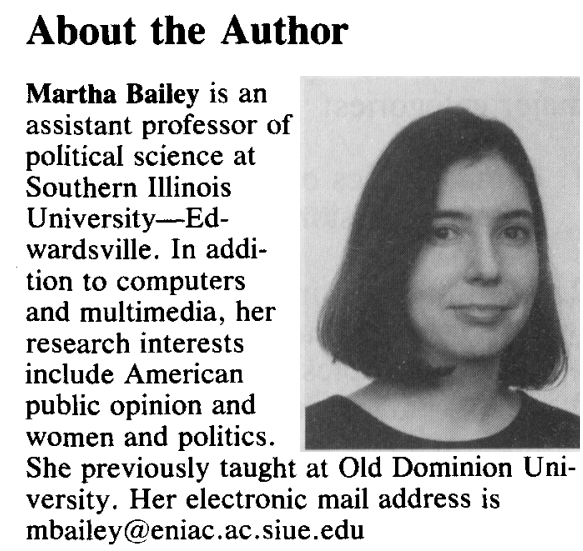

